\title{
ETNOGRAFÍA Y COMUNICACIÓN: EL PROYECTO ARCHIVO ETNOGRÁFICO AUDIOVISUAL DE LA UNIVERSIDAD DE CHILE
}

\author{
Mauricio Pineda Pertier \\ etnomedia@yahoo.com \\ Programa de Antropología Visual, UBA \\ Universidad de Chile
}

\section{RESUMEN}

Considerando la etnografía audiovisual en tanto proceso comunicativo, se analiza el caso del Archivo Etnográfico Audiovisual de la Universidad de Chile y sus experiencias en el desarrollo de etnografías audiovisuales durante los últimos ocho años. Más allá de su uso como técnica de registro de datos, la construcción y difusión de mensajes de contenido social a partir de dichos registros van conformando una praxis compleja de producción de comunicación que nos lleva a revisar críticamente la conceptualización tradicional del concepto de comunicación. En este trabajo nos proponemos discutir estos modelos, planteando alternativas desde una perspectiva aplicada en un sentido ético-político en contextos locales de desarrollo.

Palabras clave: etnografía, comunicación, medios, desarrollo. 


\begin{abstract}
This article considers audiovisual ethnography as a communication process, and takes the Audiovisual Ethnographic Archive of Universidad de Chile and its experience in the development of audiovisual ethnographies during the past eight years as a case of analysis. Beyond its use as a data recording technique, the construction and dissemination of messages with social content based on the aforementioned data records constitute a complex praxis of communication production that leads us to critically review the traditional conceptualization of the concept of communication. This work discusses these models, setting forth alternatives from an applied ethno-political perspective in local development contexts.
\end{abstract}

Key words: ethnography, communication, media, development. 


\section{INTRODUCCIÓN}

La incorporación de nuevas tecnologías de registro de imagen en movimiento por parte de antropólogos y antropólogas, especialmente en las últimas tres décadas con la masificación y el acelerado desarrollo del video, ha permitido a los investigadores utilizar la cámara como una herramienta de reflexión.

A fines de 2006 me trasladé a San Pedro de Atacama, en la región chilena de Antofagasta, contratado por la Asociación Indígena Valle de la Luna, que representa a seis de los ayllus — comunidades - de etnia lickan antai que componen el poblado, para participar como antropólogo audiovisual en un proyecto de rescate de memoria oral en torno a las faenas mineras de extracción de sal que los sanpedrinos desarrollaron en Las Salinas, hoy convertidas en reserva nacional y rebautizadas como Valle de la Luna, transformándose en uno de los principales atractivos turísticos de la zona. No tardé en notar una fuerte reticencia por parte de los locales para participar en el proyecto: «No señor, gracias, ya han venido del trece —UCTV_- del TVN, del Discovery, de todos los canales a grabarnos. Siempre prometen mandar lo que graban y nunca cumplen»; «No caballero, después muestran las cosas a su pinta, nada que ver con cómo son las cosas de aquí».

Este tipo de percepciones se han generado a partir de la exposición previa de los pobladores a experiencias en las cuales han sentido injusta la forma de intercambio con el investigador/documentalista. Huelga decir que el trabajo fue infructuoso, no obstante llegó a feliz término en gran medida gracias a la constante gestión e intermediación de la Asociación Indígena Valle de la Luna. También cabe destacar que el equipo de investigación tenía algún conocimiento de los códigos culturales locales, lo cual nos permitió entablar comunicación con cierto grado de fluidez con la población. Esto se debe en gran medida a que, como señala Cardoso de Oliveira (1994), en Latinoamérica no 
estudiamos pueblos distantes, sino que estudiamos a «otros próximos» (Tilkin Gallois 2006: 306); y en nuestro país, tanto en lo espacial como en lo cultural, la gran mayoría de los chilenos desciende de los pueblos originarios y comparte con ellos una serie de elementos culturales que se trasuntan en un sinnúmero de prácticas cotidianas. Al año siguiente, junto al musicólogo Miguel Ibarra, gestioné recursos para realizar una etnografía audiovisual sobre los bailes religiosos que se practican en la fiesta patronal de San Pedro, encontrándonos con la misma reacción inicial, la cual superamos gracias al constante respaldo de la Asociación Indígena y al antecedente de nuestro anterior trabajo, cuyo producto en DVD se exhibió repetidamente y el cual distribuimos a cada interlocutor de nuestro nuevo proyecto en forma previa a las entrevistas a manera de carta de presentación.

Si bien el trabajo realizado fue exitoso y sus resultados muy bien recibidos por las comunidades participantes, es necesario resaltar que algunos grupos se negaron terminantemente a colaborar esgrimiendo argumentos similares a los expuestos más arriba, lo que, más allá de las particularidades de los proyectos señalados, nos lleva a reflexionar sobre las circunstancias que originan ese malestar en nuestros interlocutores respecto a la praxis de la investigación etnográfica y de la producción audiovisual.

El Archivo Etnográfico Audiovisual de la Universidad de Chile fue fundado por un grupo de antropólogos en 2002 con el objeto de incorporar el uso de nuevas tecnologías a la investigación etnográfica y capacitar a investigadores en su utilización. Después de seis años de recorrido se ha realizado una veintena de etnografías audiovisuales, la mayor parte de ellas financiadas con fondos públicos destinados a la investigación, conservación, promoción y difusión de patrimonio inmaterial. Esto es posible debido a que en Chile, a diferencia de los proyectos o programas destinados a la conservación de patrimonio material, el cual se encuentra reconocido, normado y regulado con anterioridad por instituciones como el Consejo de Monumentos Nacionales. La complejidad y diversidad 
cultural de los modernos Estados latinoamericanos, donde los procesos de democratización han dado lugar a espacios de diferenciación y cierta autonomía cultural con múltiples expresiones y prácticas que progresivamente devienen en identitarias, el Estado pierde la capacidad de controlar el campo cultural «debiendo limitarse a asegurar la libertad de sus actores y las oportunidades de acceso a los diversos grupos sociales, dejándole al mercado la coordinación y dinamización de ese campo» (Martín-Barbero y Rey 1999: 33).

En el caso de Chile, frente a la creciente complejidad de la diversidad identitaria y cultural, se ha implantado un modelo intermedio bajo el cual la activación y la gestión de patrimonio inmaterial corresponde a agentes particulares que son habilitados mayoritariamente a través del financiamiento público, mediante fondos concursables, y en algunos casos privados, gracias a los beneficios tributarios que animan a las empresas a donar recursos para fines culturales y educativos.

Asumir la producción audiovisual desde la etnografía implica no sólo el aprendizaje de las técnicas y el lenguaje audiovisual desarrollado por el cine, la televisión y el video, sino que es necesario replantearse y reformular todas las interrogantes asociadas a los usos, los objetivos y los potenciales de la producción de mensajes audiovisuales desde nuestra disciplina. En este sentido, un primer paso fundamental es analizar qué entendemos por comunicación y cuáles son los medios para realizarla.

Utilizaremos la expresión «etnografía audiovisual» para referirnos a las producciones realizadas desde la praxis de los etnógrafos, diferenciándola del «documental etnográfico», entendido como las producciones cinematográficas o televisivas sobre determinados grupos o identidades. Como veremos más adelante, esta diferenciación no es gratuita, si no que deriva de diferentes modelos y prácticas comunicativas. 


\section{ETNOGRAFÍA AUDIOVISUAL Y COMUNICACIÓN}

Bastante se han señalado ya los problemas que han significado para el desarrollo de la antropología las limitaciones de nuestras formas habituales de comunicación, en tanto autoreferenciada y autocentrada, ignorando siempre las condiciones de recepción de nuestros mensajes fuera del círculo académico (Tilkin Gallois 2006: 307). Cabe señalar que tales tendencias elitistas son un resabio de los orígenes coloniales de la disciplina, donde, en la relación que establece la academia entre investigador-investigado, se trasuntan las relaciones históricas de dominador-dominado, es decir, se trata de relaciones signadas por una desigualdad de poder — recordemos que el investigado pasó en tiempos recientes de ser objeto a sujeto de estudio, lo que es un avance aunque continúe dependiendo de nosotros- Esa concepción vertical que caracterizará una buena parte de la historia de la antropología es la que progresivamente va hartando a las comunidades que estudiamos. En relación a los investigadores, Jean Rouch señala: «Cuando la investigación se completa, los antropólogos vuelven a su universidad, redactan su informe y posiblemente obtienen distinciones. ¿Cuál es el resultado para aquellos que fueron investigados? Ninguno; la irrupción del antropólogo no les arroja beneficios. La gente no lee el informe» (Rouch en Georgakas et al. 2005: 101).

En San Pedro de Atacama, los primeros antecedentes de intervención académica se remontan a la década de los cincuenta, con la llegada al pueblo de Gustavo Le Paige, sacerdote belga con conocimientos e intereses arqueológicos, quien da a conocer al mundo la riqueza arqueológica de la zona. Avalado por la posición de poder que le inviste su cargo eclesiástico, y respaldado por distintas universidades, exhumó cadáveres, confiscó bienes culturales y los exhibió en el museo que creó para tal fin.

El particular estilo arquitectónico y la buena conservación del mismo llevaron a las 
autoridades a patrimonializar el poblado durante los años ochenta, lo que fomentó su explotación turística generando que diversos agentes públicos y privados se apropiaran del poblado y causando un desplazamiento de los pobladores hacia los ayllus -comunidadescircundantes. Los dueños de negocios relacionados con el turismo tienden a contratar músicos de Santiago o de Bolivia en lugar de sanpedrinos porque consideran que «éstos se asemejan más a la imagen andina que esperan encontrar los turistas». En medio de este proceso, el museo del sacerdote Le Paige pasó a ser administrado por la Universidad Católica del Norte y los sanpedrinos se convirtieron en sujetos tácitos de investigaciones antropológicas y arqueológicas en las cuales tienden a reproducirse las relaciones viciosas que señalamos más arriba.

En la medida que los procesos de investigación son conceptualizados en términos de una relación desigual con resabios de dominación, que resultan en una percepción de expropiación de la producción cultural sobre la que se construyen las identidades locales, surge la necesidad de reformular la praxis etnográfica. La etnografía ha sido fruto de interesantes reflexiones por parte de antropólogos y antropólogas en Latinoamérica, superando sus funciones decimonónicas de cronista y portavoz de otros, y abandonando las perspectivas del relativismo cultural que impedían la comunicación y las posibilidades de traducción intercultural (Tilkin Gallois 2006: 306) para asumir que, en tanto construcción dialéctica producto del encuentro con otros y de un diálogo intercultural, implica una mutua comprensión a partir del reconocimiento de las diferencias.

El trabajo etnográfico puede entonces «contribuir a ese reconocimiento igualitario de la diferencia» (Bartolomé 2003: 208). Tal reconocimiento implica aceptar al otro dentro de una relación horizontal de construcción dialéctica de sentidos y mutuo desarrollo. El otro pasa, en esta perspectiva, de ser un informante a ser un interlocutor. El término no es gratuito y nos lleva a repensar la etnografía como una relación vincular fundada en 
procesos de comunicación.

Cabe señalar que la etnografía audiovisual se trata de una especialización de la etnografía, compartiendo sus fundamentos epistemológicos y aplicándolos a la construcción de documentos audiovisuales que constituyen a la vez una técnica/método de investigación y una forma de expresión resultante de la experiencia intercultural. El proceso de construcción de la etnografía y el de un documento audiovisual etnográfico tiene momentos análogos:

cuando el cineasta registra en una película los gestos o los hechos que le rodean se comporta como un etnólogo que registra en su cuadernillo de apuntes las observaciones; cuando a continuación los monta es como el etnólogo que redacta su informe; cuando lo difunde hace como el etnólogo que entrega su libro para ser publicado y difundido. En todo ello aparecen unas técnicas muy similares, y en dichas técnicas ha encontrado realmente su camino el film etnográfico (Rouch 2005: 68).

La selección de determinados elementos o prácticas del grupo y la producción de documentos sobre ellos genera un impacto que saca dichos elementos de su naturalidad cotidiana por el sólo hecho de hacernos reflexionar sobre ellos, sin mencionar el recelo que produce el hecho de que a un estudioso/que viene de la universidad/un señor de afuera/etc., le pareció destacable/importante/digna de hacer una investigación —e incluso una película - sobre eso. En este sentido, la «etnografía audiovisual» genera indudablemente impactos reflexivos en las identidades locales, así como también en el investigador.

En términos académicos, la investigación en antropología se ve enriquecida no sólo por la capacidad de reproducir indefinidamente lo observado, sino por la posibilidad de proyectar el documento a las personas observadas y estudiar con ellas a partir de las imágenes de su comportamiento (Rouch 2005: 68). De esta forma, la etnografía audiovisual opera 
dialécticamente sobre la realidad creando conciencia de lo que se está viviendo (Colombres 2005a: 195).

Por otra parte, la praxis etnográfica, en tanto intervención institucional y académica sobre las culturas e identidades locales, constituye una fuente de reflexividad y de legitimación de la producción cultural que opera desde el mismo momento en que el investigador selecciona determinados elementos de la totalidad cultural (Cruces 1997: 82-83). La reflexividad que opera en el otro frente a esa legitimación puede a su vez activar procesos de reformulación simbólica de dichos elementos en función de sus construcciones identitarias. Dicho proceso de reflexividad y legitimación «constituye espacios donde pueden existir prácticas de resistencia e impugnación frente a la dominación, junto a la reproducción de hábitos y relaciones sociales instaurados por el sistema hegemónico y útiles para su reproducción» (Pérez-Ruiz 1998: 107). Esto implica que las etnografías audiovisuales pueden ser reapropiadas contrahegemónicamente por las identidades locales, transformándose en lo que Feldman-Bianco considera un instrumento de intervención político-cultural (Feldman-Bianco 2005: 293).

La ineludible responsabilidad social hacia el grupo local que conlleva la praxis de la etnografía audiovisual implica necesariamente asumir un compromiso ético y político con nuestros interlocutores (Contreras et al. 2005: 45).

En este sentido, algunos autores acentúan la necesidad de empezar a hablar de «coproducción entre los realizadores y la propia gente del conflicto, generar un vínculo que permita la confianza y el trabajo compartido, posibilitar la toma de conciencia de lo que significa un medio audiovisual puesto al servicio de los que hoy están excluidos, desamparados, o nuevos desaparecidos en la inserción laboral. Realizar la construcción del guión a partir de sus necesidades concretas, hacer del documental una herramienta para la 
liberación, una suerte de devolución: cultura y arte restituyendo la dignidad perdida» (Mirra y Buen Abad 2005: 75-77).

En este sentido, y frente a la constatación de las asimetrías comunicacionales entre poderes hegemónicos y comunidades locales en nuestros estados, numerosas ONGs y agencias estatales comenzaron a desarrollar diversos programas y proyectos de transferencia tecnológica audiovisual a comunidades indígenas en distintos países de Latinoamérica a partir de la década de los ochenta. En el caso de México, emblemático tanto por la cantidad de experiencias como por el alcance y la sostenibilidad en el tiempo de éstas, destaca el Proyecto de Transferencia de Medios Audiovisuales a Comunidades y Organizaciones Indígenas impulsado por el Instituto Nacional Indigenista a partir de 1990 (Flores 2005: 11). Esta iniciativa cristalizó en los Centros de Vídeo Indígena (CVI), presentes en varios estados de ese país, cuyas metas consisten en la difusión del trabajo creativo de los grupos indígenas mediante productos de divulgación; el fomento a la creación y reproducción de formas de expresión propias que respondan a sus necesidades y visiones actuales; y la conformación de un acervo audiovisual de sus manifestaciones culturales. Sin desmerecer en lo absoluto tan encomiable tarea, cabe señalar que, como su nombre lo indica, se trata de transferencia de tecnología audiovisual, contando generalmente con procesos de capacitación en su uso a cargo de cineastas y audiovisualistas. De esta manera, si bien se ha encarado una parte del problema, esto es, la capacidad técnica y tecnológica de producción audiovisual, no se ha dado, en términos generales, una crítica al modelo de comunicación, por lo que en muchos casos, si bien se han adaptado los contenidos a las necesidades de la comunidad, la producción audiovisual de estos centros tiende a imitar formalmente a la producción audiovisual de la televisión. Carlos Flores ilustra esta problemática en su investigación con los q'eqchi’ de Guatemala: «los jóvenes estaban expuestos permanentemente a la influencia de la televisión comercial, en donde miraban películas norteamericanas o telenovelas mexicanas, de las cuales tomaban ideas para sus 
producciones» (Flores 2005: 12-13). Al no haber información sobre otros modelos de comunicación que orienten la producción audiovisual, naturalmente se tiende a reproducir el que se conoce. No basta con poner un medio de comunicación en manos de la comunidad. Además se hace necesario dotarles de modelos alternativos de comunicación que permitan adaptar sus contenidos y necesidades informativas.

Resulta importante cuestionar nuestros conceptos sobre la comunicación. Se trata de un término de uso cotidiano y naturalizado, que en términos de crítica conceptual ha sido escasamente analizado desde las ciencias sociales. Jay Ruby plantea la existencia de un «conjunto de relaciones complejas y causales entre nuestro sistema ideológico cultural, los paradigmas de la ciencia y nuestras actitudes, en general y en la ciencia, sobre las distintas formas de comunicación visual». Y continúa sosteniendo que «nuestros valores culturales, así como nuestros conceptos científicos sobre estas formas deberán transformarse antes de que pueda emerger una antropología visual o un cine antropológico verdaderamente significativo» (Ruby 1995: 196).

La deconstrucción del modelo de comunicación imperante, así como el desarrollo de un modelo alternativo, es obra del comunicólogo y pedagogo Manuel Calvelo Ríos (2003 y 2006), cuya producción académica se encuentra inédita prácticamente en su totalidad. Como veremos, se trata de un concepto que en su seno oculta mecanismos de reproducción hegemónica.

\section{MODELOS DE COMUNICACIÓN}

\section{EL MODELO DE COMUNICACIÓN DE LASSWELL}

El modelo de comunicación que se enseña en la mayor parte de las escuelas de periodismo y comunicación tiene sus antecedentes en los estudios de propaganda cinematográfica, que 
cobran gran importancia a partir de la Primera Guerra Mundial.

Fue desarrollado principalmente por Harold Lasswell, experto en la influencia de la comunicación masiva en procesos de estabilización social. Se le llamó también modelo de la aguja hipodérmica, en el sentido de que la comunicación y la propaganda deberían funcionar como una inyección poco perceptible en el cuerpo social que contribuiría a estabilizar la vida social. Este modelo fue esquematizado por los matemáticos Claude Shannon y Warren Weaver durante la Segunda Guerra Mundial como E $\rightarrow \mathrm{M} \rightarrow \mathrm{R}-$ emisor-medio-receptor- Para entenderlo mejor es necesario remitirnos a su desarrollo histórico: este esquema fue formulado a partir del modelo de Lasswell en los bunkers de los altos mandos aliados durante la Segunda Guerra Mundial como respuesta a la problemática de bombardear aéreamente objetivos situados en el Atlántico norte, en condiciones climáticamente adversas y con mínima visibilidad, para lo que se recurrió a la radioemisión, que por entonces contaba con cierto desarrollo técnico.

La estrategia básica consistía en enviar la información de los objetivos al piloto en forma de un mensaje que se repetía en iteraciones del mismo a fin de evitar la distorsión por interferencias. Una vez que el piloto lograba captarlo en su totalidad, confirmaba la recepción reiterándolo a los emisores, proceso que en este modelo se conoce como «retroalimentación». Como vemos, se trata de un modelo unidireccional y vertical propio del orbe militar - que busca que el receptor realice las acciones requeridas por el emisor. Es en esencia un «modelo de manipulación». La retroalimentación consiste en la confirmación de la información recibida por parte del receptor o destinatario.

Este modelo fue central en la considerable producción de los investigadores de la Mass Communication Research sobre propaganda y las conexiones entre comportamientos y persuasión (Martín-Barbero y Rey 1999: 65), que constituyen el cuerpo central de la 
autodenominada teoría de la comunicación.

\section{APLICACIÓN DEL MODELO E-M-R EN MEDIOS AUDIOVISUALES}

Sin contar con alternativas por ese entonces, este modelo fue incorporado desde sus inicios al desarrollo conceptual y tecnológico de la televisión, por entonces incipiente, llegando a transformarse en el medio más masivo de transmisión de información. A partir de ese momento tendrá un impacto cada vez mayor en la sociedad en la medida en que influye sobre los actores sociales que intervienen activamente en la realidad social (Martín-Barbero y Rey 1999: 57). Se tiende a estandarizar la opinión homogenizándola a partir de los énfasis mayoritarios que fabrica (Martín-Barbero y Rey 1999: 71) y se convierte «en el árbitro del acceso a la vida social y política» (Bourdieu 1997: 28) transformándose así en «un colosal instrumento de mantenimiento del orden simbólico» (Bourdieu 1997: 20).

Dadas las investigaciones sobre propaganda cinematográfica y su uso potencial como factor de estabilización social, que constituyen los antecedentes teóricos del uso social de la televisión, podríamos decir que se trata de un medio que nació pensado para la masividad y la masificación de la población.

En el contexto latinoamericano, los medios masivos como el cine y la radio cobrarán gran importancia en el proceso de modernización de los Estados durante la primera mitad del siglo XX; «La idea de modernidad que sostiene el proyecto de construcción de naciones modernas en esos años articula un movimiento económico — entrada de las economías nacionales a formar parte del mercado internacional- a un proyecto político: constituirlas en naciones mediante la creación de una cultura y una identidad nacional». (Martín-Barbero y Rey 1999: 31). A partir de fines de la década de los sesenta y durante los setenta del siglo pasado, la televisión fue también utilizada en forma propagandística por los gobiernos en 
turno con fines de concientización política a fin de implantar modelos económicos.

Particularmente durante los años ochenta se experimentará en nuestro continente, en materia de televisión, un notorio afianzamiento de lo privado junto a un debilitamiento de lo público (Martín-Barbero y Rey 1999: 51). En el caso de Chile, los canales de televisión nacieron al amparo del quehacer universitario, siendo financiados desde el Estado con fondos destinados a la entonces educación superior pública. Posteriormente, la ley de televisión de 1969 contempló que los canales de recepción abierta se financiaran con fondos privados por concepto de publicidad, decantando así los actuales estándares de contenido de la parrilla programática, como ocurre en la mayor cantidad de los medios televisivos latinoamericanos, «siendo más sometida que cualquier otro universo de producción cultural a la presión comercial, a través de los índices de audiencia» (Bourdieu 1997: 51).

Esta presión implica sacrificar la profundidad y calidad de los contenidos en función de la amplitud de la audiencia, generando una forma de comunicación vacía de contenidos, o de contenidos banales compartidos previamente por los interlocutores, que no aporta desarrollo a ninguna de las partes involucradas.

Por otra parte, la televisión, a partir del modelo de «comunicación» en que se funda, consiste en un medio de transmisión de información en un solo sentido, es decir, de emisor a receptores, siendo por tanto irrebatible. Manuel Calvelo (2006: 67) nos recuerda que alguien dijo una vez que, tal como la radio comercial podría considerarse «el sordo que habla a los mudos», la televisión a su vez deviene en «el gran tuerto que mira paralíticos», dando por sentado que el espectador es un ente pasivo que sólo recibe la información y actúa en consecuencia. El medio televisivo inspirado en este modelo contempla la retroalimentación en base a esporádicas encuestas de preferencias sobre los canales o 
programas emitidos, las que hoy son progresivamente reemplazadas por los people meter: modernos aparatos que registran la recepción. No obstante, poco sabemos de los parámetros utilizados para medir la representatividad de la audiencia.

En el caso de Chile, se trata de 400 aparatos cuya distribución depende de los target de las empresas de publicidad. Es decir, que si la empresa auspiciadora de determinado programa vende camionetas, los people meter se reubicarán conforme al público que potencialmente compraría la camioneta. Es decir, la representatividad de las preferencias del público, argumento que esgrimen los profesionales del medio cada vez que se pone en tela de juicio la calidad de los contenidos que se emiten es, cuando menos, bastante cuestionable.

Calvelo plantea que, si consideramos los orígenes etimológicos del término comunicación, debemos remitirnos entonces al communisfacere, es decir, al «hacer en conjunto», aludiendo a una acción colectiva que requiere de un elemento fundamental: la interlocución (Calvelo 2006).

La interlocución supone sujetos activos en el proceso de intercambio de mensajes, donde estos mensajes generan un efecto de interacción dialéctica que modifica progresivamente las percepciones de ambas partes. La ausencia de interlocución en el modelo de Lasswell nos indica lo que es: un modelo de transmisión vertical de información cuyo objetivo consiste en modificar la conducta del destinatario. Los medios que se desarrollan bajo este modelo no pueden sustraerse de las condiciones básicas del mismo, esto es, un receptor pasivo y la ausencia de interlocución — condición que consideramos básica en todo proceso comunicativo- . En base a estas formulaciones, Calvelo afirma que la televisión no puede considerarse un medio de comunicación, sino cuando más un medio de transmisión de información o, dicho más correctamente, un medio de manipulación. Por otra parte, el problema fundamental de la producción televisiva tiene que ver con su financiación a través 
de la publicidad de las empresas privadas, quienes presionan, a través de las restricciones de auspicio, en pos de la espectacularidad y en detrimento de la calidad de la información. En este sentido, el discurso audiovisual, la imagen masiva de esos «otros» que construye la televisión, está condicionado por los auspiciadores, quienes buscan la espectacularidad de la imagen mediante la explotación de fantasías exotistas que, al descontextualizar los elementos y prácticas culturales expuestos, distorsiona el sentido que tienen en el seno de su comunidad de origen al tiempo que masifican dicha distorsión.

Son esas descontextualizaciones, esas distorsiones de la imagen, las que explican el malestar de las comunidades al someterse al registro audiovisual desde una posición dominada, en relaciones de «comunicación» signadas por la verticalidad y la imposición de imágenes distorsionadas que escapan a su control. De este modo, cobran mayor sentido las palabras de Adolfo Colombres: «Así como los indígenas han rechazado a la antropología «pura» por su connivencia con el colonialismo, por servir a los fines del opresor y no a los suyos, se opondrán también al cineasta que pretenda filmarlos contra su voluntad y participación y sin explicar sus propósitos, conscientes de que eso sólo puede conducir a la distorsión de su imagen» (Colombres 2005b: 43).

Así conceptualizado, este modelo no nos sirve para abordar la praxis de una etnografía audiovisual. Ruby señala que existe un conjunto de relaciones complejas y causales entre nuestro sistema ideológico cultural, los paradigmas de la ciencia y nuestras actitudes, en general y en la ciencia, sobre las distintas formas de comunicación visual. De ahí la necesidad de construir una nueva teoría de la comunicación a través de la imagen que se adapte a las necesidades de la antropología (Ruby 1995: 196-197).

\section{EL MODELO DE COMUNICACIÓN PARA EL DESARROLLO O DE LA EDU-COMUNICACIÓN}

Existe otro modelo de comunicación mucho más desconocido por cuanto está 
prácticamente ausente tanto en medios masivos como en centros de formación académica. Se trata del modelo de interlocución, caracterizado por la relación interlocutor-mediointerlocutor, esquematizada como $\mathrm{I} \rightarrow \mathrm{M} \rightarrow \mathrm{I}$ —de aquí en adelante IMI — que implica a dos —o más— sujetos activos en el proceso de intercambio de mensajes.

Este modelo supone un cambio cualitativo en el sujeto al recibir e incorporar el mensaje, que se manifiesta en la reformulación y enriquecimiento del mismo al serle incorporados nuevos elementos por parte del interlocutor. Es decir, la interlocución genera un desarrollo en los sujetos del proceso comunicativo.

En este modelo, el productor de mensajes se desplaza de la posición del emisor —en el modelo anterior - al del medio, cumpliendo así el rol de comunicador entre interlocutores diversos. En el caso que nos interesa, uno de los interlocutores es la comunidad o el grupo local, y el otro son los grupos hegemónicos o decisores políticos o económicos —léase el Estado- u otras comunidades o grupos locales. En este modelo sólo hay comunicación en la medida en que los mensajes que intercambian los interlocutores son producto de un trabajo conjunto (Calvelo 2006: 14), es decir, se trata de un modelo participativo que fomenta la reflexión y el desarrollo de los interlocutores. Alejandro Barranquero señala que «el diálogo y la comunicación horizontal son procesos privilegiados para promover la capacidad crítica y el progreso del individuo y la sociedad hacia una existencia más digna y humana» (Barranquero 2007: 117). También señala que este modelo «vendría a resolver las contradicciones entre conocimiento/reflexión/teoría y acontecer/acción/praxis, generando «Concientización» en el doble sentido político-pedagógico freireano, como conocimiento o descubrimiento de la razón de las cosas - y como conciencia — de sí, del otro, de la realidad-, siempre acompañada de acción transformadora y política» (Barranquero 2007: 117). Este autor también señala que a partir de los años ochenta, con el cuestionamiento que ha sufrido el concepto de desarrollo, algunos autores prefieren hablar de comunicación 
para el cambio social.

Así visto, se trata de un modelo que se nos presenta como idóneo para abordar la construcción de discursos audiovisuales sobre el encuentro intercultural que supone la etnografía, evitando la distorsión y descontextualización de los elementos representados, y ocasiona su expropiación por parte de proyectos identitarios hegemónicos en detrimento de su potencial uso como referente de las identidades locales. Estamos así en condiciones de abordar la etnografía como praxis comunicacional, atendiendo a la recepción de dicha etnografía, contribuyendo así a concebirla como un verdadero diálogo intercultural con otros, un canal concreto de comunicación entre dos mundos, el del observador y el del observado (Guarini 2005: 162).

Este modelo ha resultado de gran eficacia para la capacitación en diferentes áreas geográficas y ámbitos tales como el desarrollo rural y agrícola, la salud y nutrición, los derechos civiles y culturales, el medioambiente, la población, el género, la paz, la infancia, las catástrofes, etc. (Barranquero 2007: 118).

\section{APLICACIÓN DEL MODELO I-M-I EN ETNOGRAFÍA AUDIOVISUAL}

Los investigadores que conformamos el Archivo Etnográfico Audiovisual del Departamento de Antropología de la Universidad de Chile adoptamos este modelo ya en nuestros primeros trabajos, dado que sus modos de producción audiovisual se adaptan con facilidad a los requerimientos particulares del trabajo de campo propio del etnógrafo, constituyendo cada una de las etnografías audiovisuales el producto del encuentro, el reconocimiento y el compromiso con nuestros interlocutores. Así se produce lo que Miguel Alberto Bartolomé describe como «un intercambio de conocimientos y no de mercancías, una relación social igualitaria y no una extracción de información. [...] Para lograr una 
interlocución equilibrada son necesarias una actitud ética y una conducta personal orientadas por el respeto mutuo y por el reconocimiento del valor del diálogo, que sólo resultan factibles de ser construidas a partir de la amistad y la confianza». (Bartolomé 2003: 209-210).

De esta manera, compartiendo abiertamente nuestro trabajo como etnógrafos audiovisuales con las comunidades y personas con las que trabajamos, hemos logrado nuestros objetivos de construcción mutua de conocimientos. Al cabo de estos siete años, la experiencia se ha traducido en más de una veintena de etnografías audiovisuales sobre temáticas diversas como fiestas religiosas, música tradicional, memoria obrera, arqueología, cultura indígena, educación intercultural, artesanía, etc. Cada una de ellas ha tenido un impacto enriquecedor en las comunidades donde se trabajó y en nosotros mismos.

En términos de metodología de trabajo, en primer lugar se abandonó la noción tradicional del etnógrafo como «observador» u «observador participante» y se remplazó por la de un «participante activo», esto es, asumir plenamente que el investigador modifica las condiciones en que se desenvuelven sus interlocutores, transformándose así en un activo interventor de la cultura. Si bien esto puede escandalizar a algunos, cabe decir que las comunidades locales se encuentran expuestas a todo tipo de intervenciones: del Estado, las empresas forestales, las mineras, las petroleras, etc., quienes persiguen un beneficio propio. En cambio, se nos pide a los investigadores sociales, quienes tenemos algún conocimiento de las dinámicas de los grupos y su valor social y cultural, que nos mantengamos al margen de la intervención. Dicha abstención sólo beneficia a los poderes hegemónicos en detrimento de los intereses de la comunidad. Por otra parte, dicha intervención se fundamenta en el hecho de que, como señalamos más arriba, en América Latina no estudiamos a otros, sino a nosotros mismos. La otredad no es sino una distorsión que origina el colonialismo a nivel metodológico en la disciplina antropológica, dado su origen 
en la Europa colonialista. En mi caso, como chileno, provengo de un país con una inmensa mayoría indígena ya que casi todos descendemos de los pueblos originarios, si bien las autoridades, en la Ley Indígena, sólo consideran minorías étnicas a quienes cumplen exigencias formales como la lengua, apellidos, etc.. Así, como «indio», no tengo problema alguno en entrometerme en asuntos «de indios» e intervenir cuándo y cómo me parezca, ya que con o sin reconocimiento legal de mi estatuto indígena, mi accionar se encuentra en la lógica del beneficio de un «nosotros». Un nosotros que se origina en una historia compartida y en una situación común de ser ambos, investigadores y comunidad, sujetos de la crisis del sistema político-económico neoliberal, donde el nosotros se construye en la praxis comunicativa de la interlocución.

Una vez asumida nuestra intervención en las comunidades, debemos aceptar que la información obtenida para el diseño del trabajo de una investigación o investigación audiovisual o proyecto documental, se enmarca en un intercambio mucho más amplio y complejo, signado por los intereses de nuestros interlocutores. Es decir, la información correspondiente a la investigación formal se encuentra contextualizada en conversaciones que van de lo humano a lo divino, dentro de las cuales surgen múltiples ideas, iniciativas y nuevos proyectos. Mi primera etnografía audiovisual, Lora: el baile de los negros, surgió de mi investigación de tesis de grado sobre la fiesta de la Virgen del Rosario en la localidad de Lora, la cual no contemplaba el uso de audiovisual. No obstante, a pedido de la población, realizamos el registro en video de la fiesta y posteriormente, también en base a la solicitud de la comunidad, reconstruimos la historia reciente de estas expresiones. «¿Por qué no entrevista a los más viejos? No ve que después se mueren y se pierde la historia», fueron las principales inquietudes que manifestó la comunidad. Estos registros, ordenados y editados en formato documental, fueron presentados a la comunidad para su discusión, comentarios, correcciones y aprobación, resultando en nuestra primera obra de etnografía audiovisual. Sin embargo, lo interesante son los procesos que continúan desarrollándose 
después del estreno de la misma y su devolución a la comunidad. Uno de los primeros impactos, de carácter reflexivo, consiste en la discusión que llevará a un proceso de reetnificación de los lorinos, asumiendo y reformulando identidades étnicas latentes por un siglo debido a la discriminación. La vergüenza y el silencio han dado paso al orgullo y a la autovaloración y la reivindicación de sus orígenes, integrándose varios miembros a las asociaciones indígenas que se comenzaron a formar en la zona. La transmisión de Lora: el baile de los negros por la televisión regional generó un incremento considerable en la asistencia a la festividad, lo que se consideró como una fuente de orgullo y satisfacción para la comunidad. Incluso, y como fenómeno a considerar, los documentalistas y sus cámaras pasaron a convertirse en un indicador del éxito de la fiesta: «Este año —la fiesta— estuvo más o menos. ¿Se fijó que andaban menos cámaras que el año pasado?» Por mi parte, esta experiencia me permitió ir redescubriendo mis propios orígenes, ya que tanto los lorinos como los isleños — de Isla de Maipo, de donde mi familia es originaria-, descendemos del mismo grupo étnico —los promaucaes de Chile central, convenientemente considerados extintos hace siglos por la historia oficial cuyo fin es justificar el Estado nacional republicano-, comenzando así un desarrollo conjunto de nuestro conocimiento histórico. Además he sido aceptado en la comunidad al punto de pasar a formar parte del baile desde 2010 y ser considerado como werkén-mensajero de la Asociación Indígena Pikum Mapu de Licantén.

A nivel local, el éxito que supuso este proyecto y su exhibición en colegios y liceos de la comuna generó interés en realizar nuevos proyectos. Don Hernán Calquín, entonces director del liceo de Licantén — cabecera de la comuna donde se emplaza Lora- y director de la Asociación Indígena Pikum Mapu de Licantén, se contactó con nuestro equipo a comienzos de 2005 para comenzar a desarrollar conjuntamente un proyecto para rescatar elementos de la memoria indígena de la zona. Dicha iniciativa cristalizó en la miniserie Nuestras huellas: cultura y memoria indígena en Licantén, que continuaba con el proceso 
de reconocimiento y valoración social de las identidades indígenas y donde además participó activamente el realizador indígena Matías Calquín. Esta relación de interlocución con la comunidad dio origen a varios proyectos etnográficos-audiovisuales, como Vichuquén: mitos ancestrales (2006) y Nuestras huellas: tradiciones productivas indígenas en Vichuquén (2007), donde también participó Matías Calquín antes de partir a trabajar en televisión.

El trabajo y la relación con los habitantes de Vichuquén — comuna y pueblo vecino a Licantén- generó dinámicas similares, dando origen a nuevas etnografías audiovisuales: «Aquí habría que hacer algo respecto a las cantoras; son viejas y quedan re pocas» inquietud que acabaría materializándose en Cantoras de Vichuquén (2006)—; «¿Por qué no hacen videos sobre la gente de los telares? Ya casi se están acabando» —así emprendimos en 2008 el proyecto Hebras de nuestra cultura: el arte textil en Vichuquén-. En todos los casos, los proyectos surgieron de las necesidades expresadas por la comunidad e invariablemente la recepción fue positiva. En términos generales, una de las claves para asegurar que como investigadores fuéramos bien recibidos, consistió en dejar claro que el trabajo no era ni para la televisión ni para la universidad, sino para la misma comunidad y para otras similares. En este sentido, una de las preocupaciones que se manifestó en todas las ocasiones tenía que ver con los derechos asociados a la producción. Dados los vacíos legales, que en Chile expresamente no protegen las expresiones tradicionales y dejan todos los derechos en manos del productor (Pineda 2010: 17), se optó por dar a la comunidad libre albedrío sobre el destino de las copias. He comprobado con gran satisfacción que en varias localidades se venden copias piratas a los turistas.

Es en esta dinámica cuando inicia nuestro contacto con las comunidades de San Pedro de Atacama. Quien nos contactó con la Asociación Indígena Valle de la Luna fue el arqueólogo Ulises Cárdenas, viejo compañero de la universidad perteneciente a la etnia 
lickan antai como se autodenominan a pesar de que la Ley Indígena los instituye legalmente como atacameños- y miembro activo de dicha organización.

Los vínculos necesarios para la realización se construyeron participando activamente en diversas instancias: asistiendo e interviniendo con nuestras experiencias en las reuniones de la comunidad con los empresarios del sector turístico; acudiendo y participando en diversas instancias festivas y rituales como el carnaval, día de todos los santos, pagos a la pachamama y a los abuelos, etc.; prestando ayuda en múltiples situaciones — cargar sacos de arena para la parroquia del ayllu de Séquitor, por ejemplo—; grabando un disco para un viejo cantor de coplas, etc. Es decir, se estableció un compromiso ético, político y concreto con la comunidad, que trasciende largamente los estrictos objetivos científicos del quehacer investigativo antropológico. Las críticas académicas que hemos recibido a lo largo de nuestro recorrido, en el sentido de que el científico antropólogo se debe a la academia y no a las comunidades, es un resabio de esa ciencia que estudiaba a los otros, precisamente porque para el europeo y su academia los «indios» constituíamos una otredad. En nuestro contexto, donde mayoritariamente hay un «nosotros», más bien cabría criticar a la academia por su profunda desconexión con nuestra realidad social y cultural. ¿Para quién se está generando el conocimiento? ¿Qué tipo de conocimiento estamos generando? El reconocido etnocineasta argentino Jorge Prelorán señala que «Generalmente somos «nosotros» los que vamos a observar «otras» culturas desde un pináculo etnocéntrico de autoridad y supremacía tecnológica» (Prelorán 1995: 132).

El modelo de comunicación para el desarrollo considera la comunicación como la condición fundante de todo desarrollo humano —económico, ecológico, social, afectivo, intelectual, etc.—, e implica reconocer a nuestros interlocutores —grupos locales, habitantes rurales o indígenas - como sujetos de desarrollo. La academia no debería perder de vista que el desarrollo, entendido en los términos que hemos planteado con anterioridad, 
es su fin último. Prelorán planteaba que «la meta final de un antropólogo debería ser obtener los conocimientos necesarios para poder mejorar la humanidad, en lugar de estériles ejercicios académicos» (Prelorán 1995: 134), y criticaba duramente a aquellos antropólogos de países del primer mundo que conseguían sumas considerables para realizar tales ejercicios intelectuales en zonas del tercer mundo donde la gente estaba padeciendo de hambre o enfermedades a causa de la pobreza, señalando que «tal estudio debe considerarse no sólo estúpido, sino escandaloso» (Prelorán 1995: 134).

\section{A MODO DE CONCLUSIÓN}

Quisiera en este punto volver al tema de cómo la incorporación del modelo de comunicación para el desarrollo en la conceptualización de la praxis etnográfica puede generar beneficios tanto para el investigador como para las comunidades.

En octubre de 2010 presencié los trabajos de limpia de canales en la localidad de Socaire, ubicada a $100 \mathrm{~km}$ al sudeste de San Pedro de Atacama. La actividad es uno de los últimos trabajos comunitarios y colectivos que realiza la comunidad, e incluye complejos rituales de agradecimiento y ofrenda a las aguas y la vertiente. Dado que en ese entonces comenzaba a planificar mi investigación doctoral sobre patrimonio e identidades indígenas, centrándome en el patrimonio inmaterial y sus efectos en la comunidad, y observando que los socaireños tenían una actitud bastante reticente hacia los procesos de patrimonialización, me pareció interesante evaluar la posibilidad de realizar mi investigación en ese lugar y de poner a prueba nuestro planteamiento teórico-metodológico sobre el modelo de comunicación para el desarrollo en la praxis etnográfica audiovisual. Yo sabía que los socaireños eran extremadamente reticentes al registro de sus prácticas tradicionales y más aún a las de carácter ritual. Pensé que la cámara me daría la oportunidad de entablar relaciones con la comunidad. Así, me dispuse a grabar las faenas con el aval de uno de los miembros, que aceptó que grabáramos a su familia durante los 
trabajos; «si alguien le dice algo, dígale que yo le di permiso». Así transcurrió la jornada sin novedad hasta que, al terminar los trabajos, todos se sentaron en una ladera del cerro que formaba un anfiteatro natural y se dispusieron a celebrar consumiendo vino, cerveza y aloja —-fermentado de semillas de algarrobo - mientras los maestros de ceremonias realizaban el ritual correspondiente. Un miembro de la comunidad reparó en mi cámara y me solicitó que lo grabara cuando fuese su turno de entregar su ofrenda para el ritual. Sin embargo, al realizar el registro fui interpelado por el jefe de trabajos comunitarios, quien señaló que debía ser el conjunto de la comunidad quien diese la autorización para la grabación, por lo que me dirigí a la población. Apenas alcancé a presentarme, ya que cuando mencioné que era antropólogo una mujer se puso a vociferar: «¡fuera!, ¡fuera!, ¡que se vaya!». La mujer argumentó que con ese registro yo me iba a hacer rico y que después ni siquiera iba a dejarles una copia. Intenté rebatir alegando que mi compromiso era entregarles una copia de todo lo que registrara. Su respuesta fue tajante: «¡Los antropólogos nunca cumplen lo que prometen!». No me quedó de otra que prometer que ya no seguiría grabando. No obstante, le entregué la cámara al amigo que nos había permitido grabar a su familia y le pedí que continuara con el registro. Al finalizar la jornada me devolvió la cámara y vacié la totalidad del contenido en un DVD que fui a entregar al día siguiente al presidente de la comunidad para que se la mostrara a los demás, según me había comprometido. Con él tuvimos una interesante conversación sobre el destino de los registros de los antropólogos, la relación entre los investigadores y la comunidad, la utilidad que tales registros tendrían si la comunidad tuviese algún control sobre su producción y uso, etc. Me preguntó por nuestra institución —el Archivo Etnográfico Audiovisual—, a qué nos dedicábamos y cómo funcionábamos, cómo nos financiábamos, etc. Aproveché para señalarle que ellos mismos como asociación indígena podían solicitar estudiantes en práctica de antropología para realizar investigaciones de interés de la comunidad. Le conté que en otros lugares, como en el altiplano boliviano y en las comunidades de migrantes aymaras en Buenos Aires, había surgido la figura del «padrino 
de cámara», persona designada por la comunidad para realizar registros para la misma, lo que pareció interesarle bastante, dado lo cual me ofrecí para ser padrino de cámara en la limpia de canales del año siguiente.

Al otro día recibí una llamada telefónica del presidente de la comunidad, quien me señaló que lo que yo había grabado «estaba bastante bien» y que «ojalá lo hubiese grabado todo usted», ya que mi amigo, que no tenía entrenamiento en cámara, iba haciendo comentarios que quedaban grabados en la pista de audio y que en algunos casos denostaban a algunos de los miembros que participaban. Por este motivo me pidió, si era posible, que editara el registro y le enviara un nuevo DVD, ya que el material les interesaba. Así lo hice, eliminando los comentarios y algo de metraje redundante. Intencionalmente dejé una toma en que mi amigo grabó uno de los discursos del capitán gritando: «iapaga la cámara!, ¡apágala!, ¡no se puede grabar!», mientras azotaba la cámara con una varilla. El camarógrafo incidental le respondía enfocando al resto de la comunidad: «ipero mírelos!, ¡si están todos con cámaras!, ¡o la cosa corre para todos o para ninguno!».

Dos días después recibí una nueva llamada del presidente de la comunidad. Me señalaba que habían quedado muy conformes con el registro editado y me preguntaron por mi disponibilidad de tiempo y tarifas, ya que necesitaban realizar varios registros para difundir y promocionar diversos elementos que les interesaba explotar como recurso turístico.

Esta experiencia, por demás sencilla, ilustra cómo el plantearse el trabajo de investigación en terreno en términos de una interlocución con los miembros de una comunidad, esto es, asumiendo nuestra intervención en la realidad que estudiamos como parte de una relación dialéctica, en que la modificación de ambas realidades es progresiva a medida que se desarrolla la comunicación entre ambos, resulta enriquecedora para ambas partes. En este caso, la comunidad pudo comenzar a cambiar su percepción del quehacer de los 
antropólogos - hay algunos antropólogos que sí cumplen lo prometido y éstos no sólo trabajan para la empresa privada o el Estado, sino que también pueden ser las comunidades quienes soliciten las investigaciones-. Mi intervención también les sirvió para darse cuenta de que la cámara no sólo puede «robarles» su patrimonio, sino que también puede ser una herramienta al servicio de la comunidad, útil para promover y valorar su patrimonio, así como también para facilitar su explotación como recurso de desarrollo. Por mi parte, en tanto investigador, este modelo de comunicación aplicado al trabajo etnográfico me permitió generar las instancias de interlocución necesarias para poder facilitar mi acercamiento inicial a una comunidad particularmente reticente a la realización de estudios e investigaciones en su interior, dando los primeros pasos para establecer una relación de comunicación audiovisual verdaderamente intercultural. 


\section{BIBLIOGRAFÍA}

Barranquero, Alejandro, 2007, «Concepto, instrumentos y desafíos de la edu-comunicación para el cambio social», en Comunicar, v. XV, n. 29, pp. 115-120.

Bartolomé, Miguel Alberto, 2003, «En defensa de la etnografía. El papel contemporáneo de la investigación intercultural», en Revista de Antropología Social, n. 12, Universidad Complutense de Madrid, Madrid, pp.199-222.

Bourdieu, Pierre, 1997, Sobre la televisión, Anagrama, Barcelona.

Calvelo, Manuel, 2006, Manual de producción pedagógica audiovisual. Santiago de Chile, Instituto de Comunicación e Imagen, Universidad de Chile. Documento inédito.

——, 2003, Comunicación para el cambio social. Organización de las Naciones Unidas para la Agricultura y la Alimentación, Oficina Regional FAO para América Latina y el Caribe.

Cardoso de Oliveira, Roberto, 1994, «O movimento dos conceitos na antropologia», en Revista de Antropología, n. 36, FELCH, Universidade de Sao Paulo, pp. 13-31.

Colombres, Adolfo, 2005a, «El cine y los medios audiovisuales como soporte de una nueva oralidad de los pueblos indígenas», en Cine, antropología y colonialismo, compilado por Colombres, Adolfo, Del Sol, Buenos Aires, pp. 191-203.

—_, 2005b, «Prólogo», en Cine, antropología y colonialismo, compilado por Colombres, Adolfo, Del Sol, Buenos Aires, pp. 15-48. 
Contreras, Rafael, Juan Pablo Donoso y Mauricio Pineda, 2005, «El video antropológico como herramienta para el endodesarrollo», en Revista Werken. Antropología, Arqueología e Historia, n. 6, Universidad Internacional Seek, Santiago de Chile, pp. 39-48.

Cruces, Fernando, 1998, «Problemas en torno a la restitución del patrimonio. Una visión desde la antropología», en Revista Alteridades, año 8 n. 16, julio-diciembre, UAM Iztapalapa, México. D. F., pp. 75-84.

Feldman Bianco, Bela, 2006, «(Re)Construindo a saudade portuguesa em vídeo: histórias orais, artefatos visuais e a traduçao de códigos culturais na pesquisa etnográfica», en Desafios da imagem: fotografía, iconografía e vídeo nas ciencias sociais, compilado por Feldman Bianco, Bela y Miriam Moreira Leite, Papirus, Sao Paulo, pp. 289-303.

Flores, Carlos, 2005, «Video indígena y antropología compartida: una experiencia colaborativa con videastas Maya-Q'eqchi' de Guatemala», en Liminar. Estudios sociales y humanísticos, v. III n. 2, CESMECA, UNICACH, Tuxtla Gutiérrez, pp. 7-20.

Georgakas, Dan, UdayanGupta y JudyJanda, 2005, «Antropología visual. Entrevista a Jean Rouch», en Cine, antropología y colonialismo, compilado por Colombres, Adolfo, Del Sol, Buenos Aires, pp. 89-106.

Guarini, Carmen, 2005, «Cine antropológico: algunas reflexiones metodológicas», en Cine, antropología y colonialismo, compilado por Colombres, Adolfo, Del Sol, Buenos Aires, pp. 161-167.

Martin Barbero, Jesús y Germán Rey, 1999, Los ejercicios del ver. Hegemonía audiovisual 
y ficción televisiva, Gedisa, Barcelona.

Mirra, Miguel y Fernando Buen Abad, 2005, «Fundamentos éticos y políticos del documental social», en Cine, antropología y colonialismo, compilado por Colombres, Adolfo, Del Sol, Buenos Aires, pp. 73-86.

Pérez Ruiz, Maya, 1998, «Construcción e investigación del patrimonio cultural. Retos en los museos contemporáneos», en Revista Alteridades, año 8 n. 16, julio-diciembre, UAM Iztapalapa, México. D. F., pp. 95-113.

Pineda, Mauricio, 2010, «Gestión de patrimonio inmaterial y derechos de autor en Chile», en URL:http://es.scribd.com/doc/44354712/Gestion-de-Patrimonio-Inmaterial-y-Derechosde-Autor-en-Chile [consulta: 20 de mayo de 2011].

Prelorán, Jorge, 1995, «Conceptos éticos y estéticos en el cine etnográfico», en Imagen y cultura. Perspectivas del cine etnográfico, compilado por Ardévol, Elisenda y Luís Pérez Tolón, Diputación Provincial de Granada, pp. 123-159.

Rouch, Jean, 2005, «¿El cine del futuro?» en Cine, antropología y colonialismo, compilado por Colombres, Adolfo, Del Sol, Buenos Aires, pp. 63-72.

Ruby, Jay, 1995, «Revelarse a sí mismo: reflexividad, antropología y cine», en Imagen y cultura. Perspectivas del cine etnográfico, compilado por Ardévol, Elisenda y Luís Pérez Tolón, Diputación Provincial de Granada, pp. 161-201.

Tilkin Gallois, Dominique, 2006, «Antropólogos namídia: comentários acerca de algunas experiencias de comunicaçao intercultural», en Desafios da imagem: Fotografía, 
iconografíaa e vídeo nas ciencias sociais, compilado por Feldman Bianco, Bela y Miriam Moreira Leite, Papirus, Sao Paulo, pp. 305-319.

Fecha de recepción: 15 de octubre de 2010.

Fecha de aceptación: 3 de junio de 2011. 